Supporting Information

\title{
Formation of Bundle Assemblies of Stereoregular Polymers in Thermal Solid-State Polymerization of 7,7,8,8-Tetrakis(aryloxycarbonyl)- p-quinodimethanes
}

\author{
Takahito Itoh, ${ }^{1 *}$ Erica Morita, ${ }^{1}$ Ryouhei Takakura, ${ }^{1}$ Hiroto Nakajima, ${ }^{1}$ Takahiro Uno, ${ }^{1}$ \\ Masataka Kubo, ${ }^{1}$ Norimitsu Tohnai, ${ }^{2}$ and Mikiji Miyata ${ }^{2}$ \\ ${ }^{1}$ Department of Chemistry for Materials, Faculty of Engineering, Mie University \\ 1515 Kamihama-cho, Tsu-shi, Mie 514-8507, Japan \\ ${ }^{2}$ Department of Material and Life Science, Graduate School of Engineering, \\ Osaka University, 2-1 Yamadaoka, Suita, Osaka 565-0871, Japan
}


a)

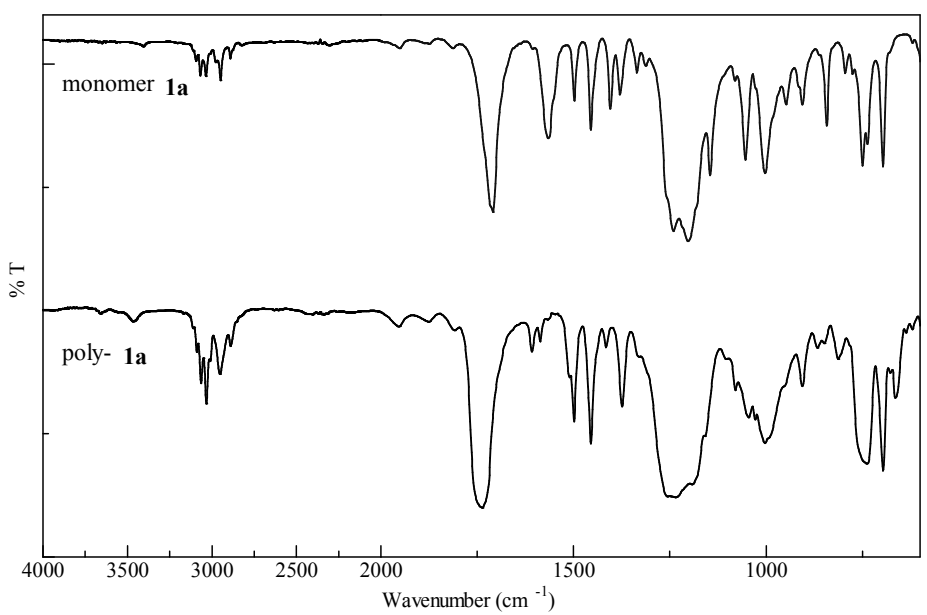

b)

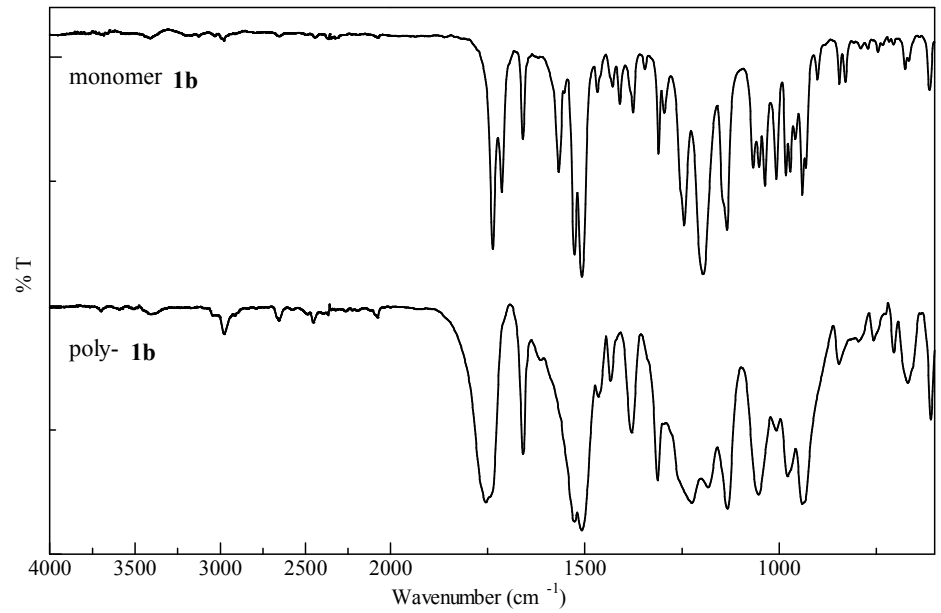

c)

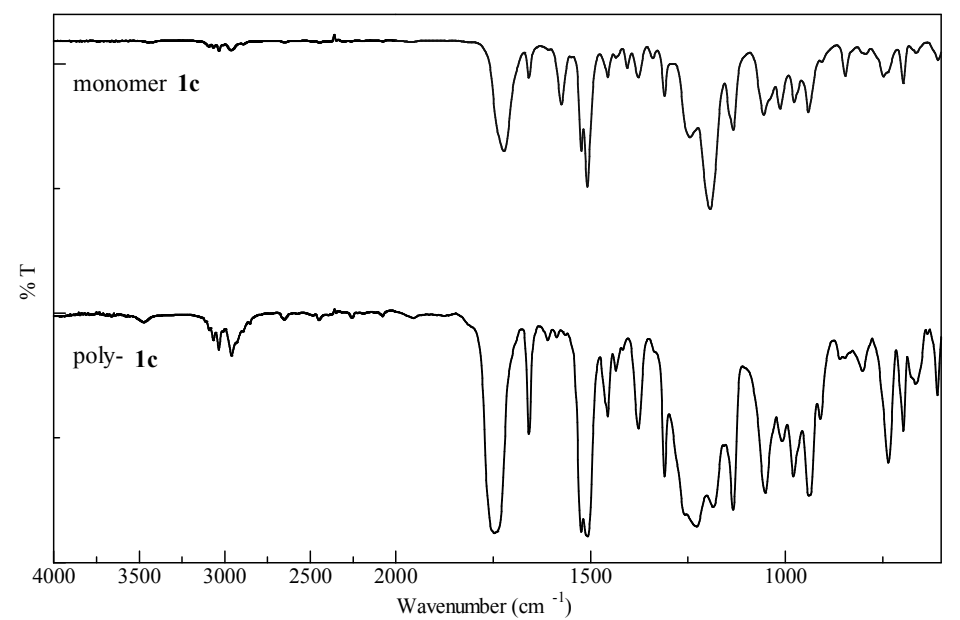

Figure S1. IR spectra (film for all except for poly-1b and $\mathrm{KBr}$ for poly-1b) of a) monomer 1a and polymer of 1a (poly-1a), b) monomer 1b and polymer of 1b (poly-1b), and c) monomer 1c and polymer of 1c (poly-1c), respectively. 
Compound 3a

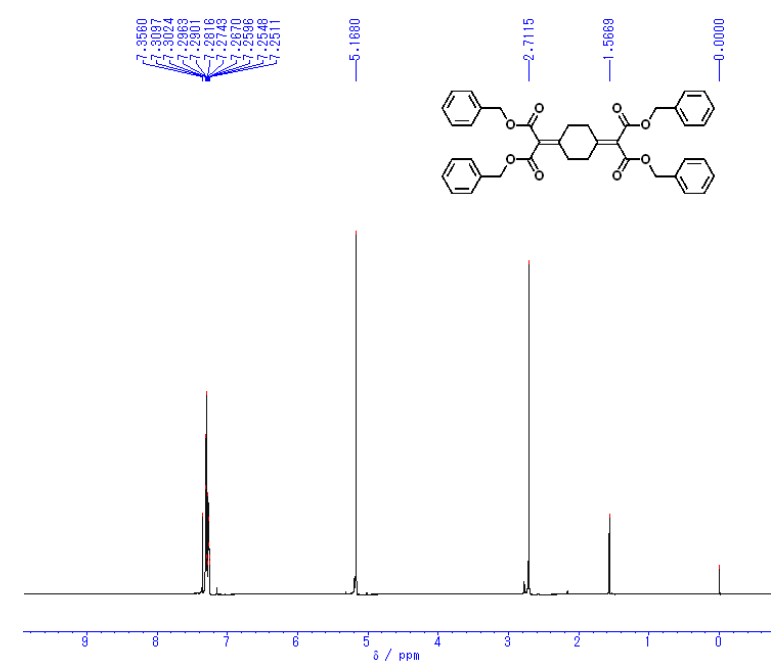

\section{Compound 1a}

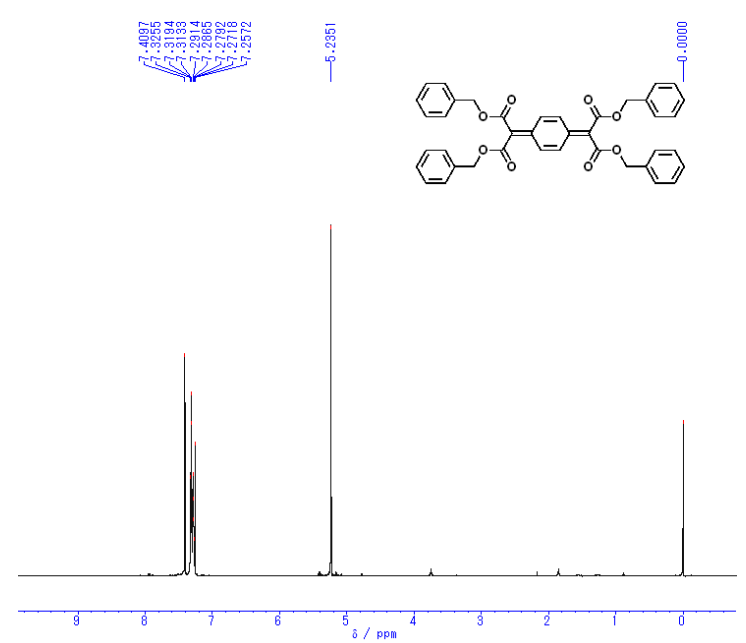

Polymer of 1a (poly-1a)

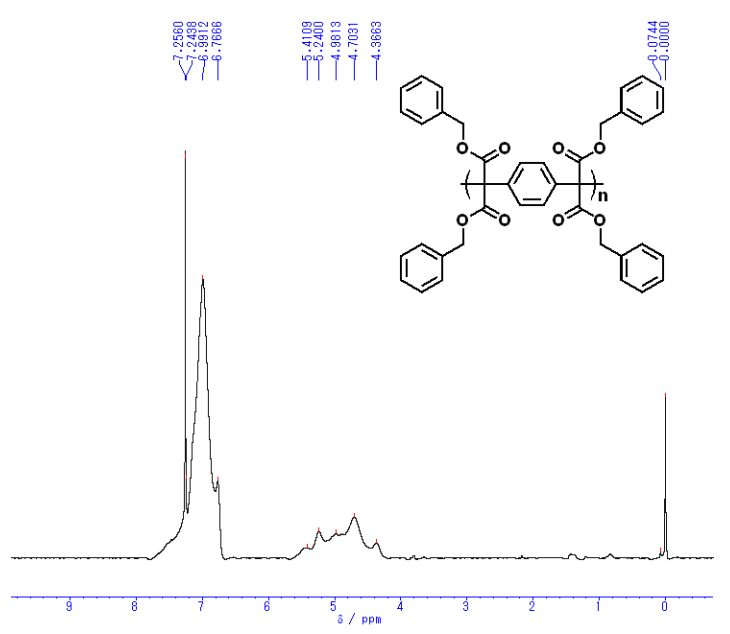

Figure S2. ${ }^{1} \mathrm{H}$ NMR spectra of $\mathbf{1 a}, \mathbf{3 a}$, and polymer of $\mathbf{1 a}$ (poly-1a) in $\mathrm{CDCl}_{3}$. 
Compound 3b

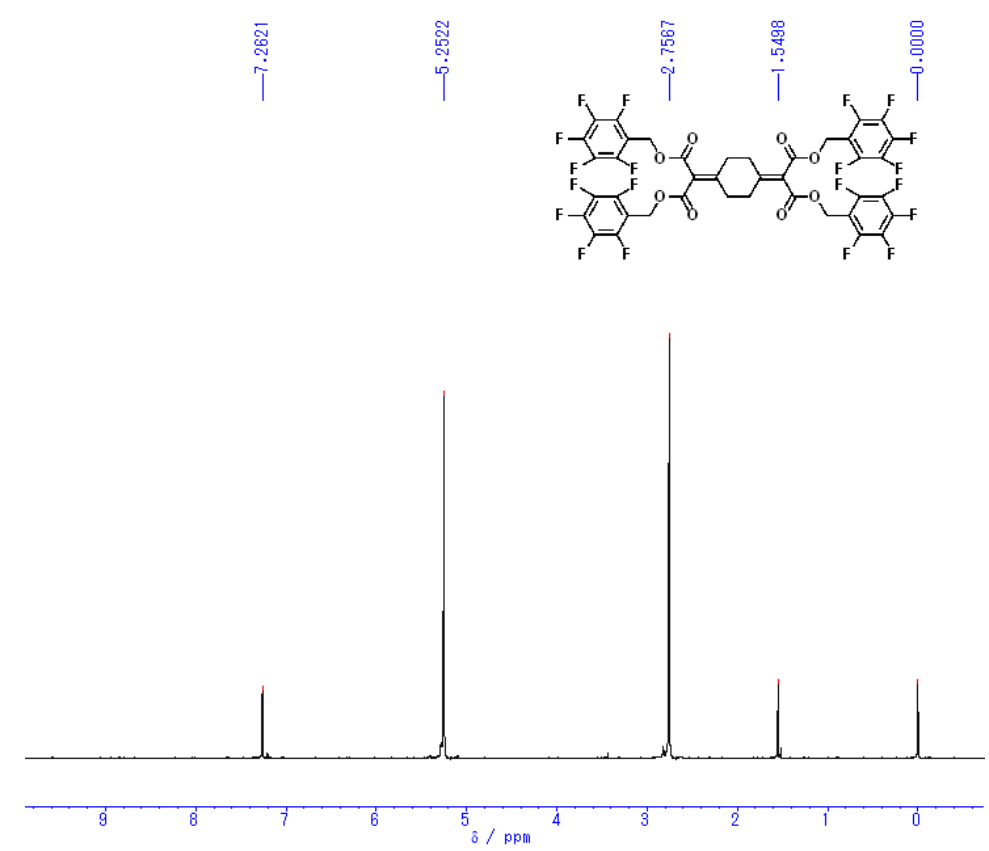

\section{Compound 1b}

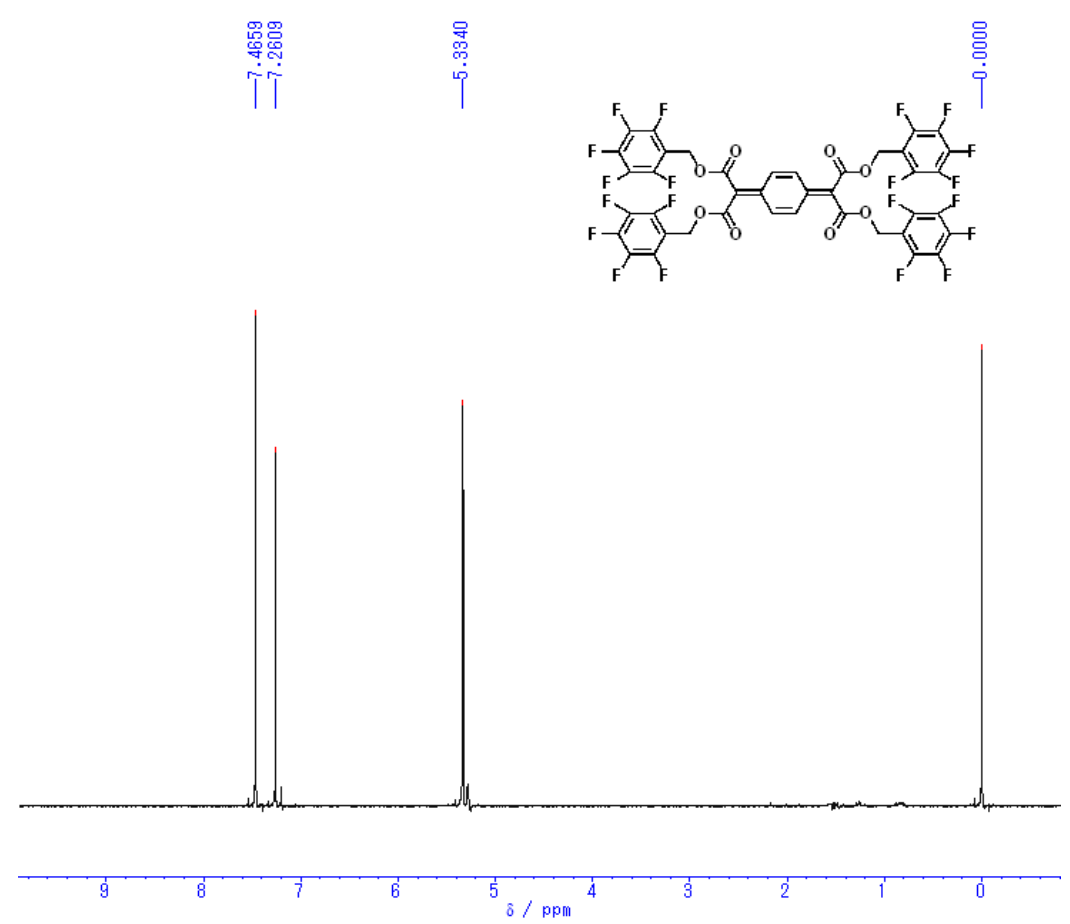

Figure S3. ${ }^{1} \mathrm{H} \mathrm{NMR}$ spectra of $\mathbf{1 b}$ and $\mathbf{3 b}$ in $\mathrm{CDCl}_{3}$. 
Compound 2

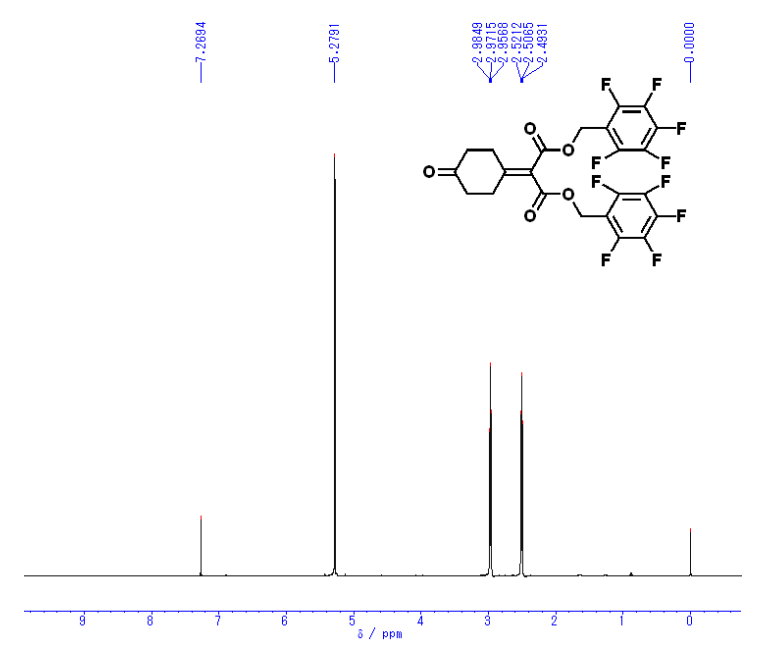

Compound 1c

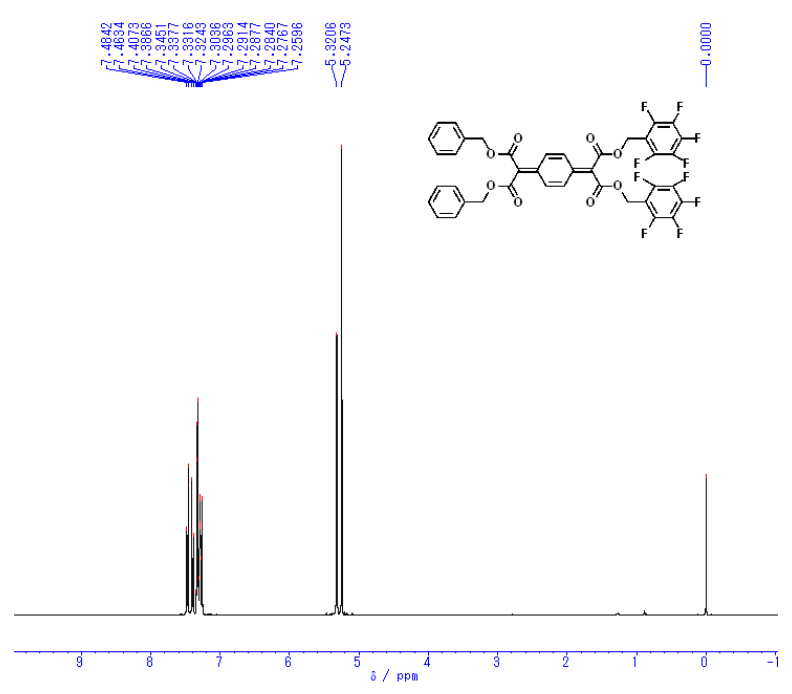

Compound 3c

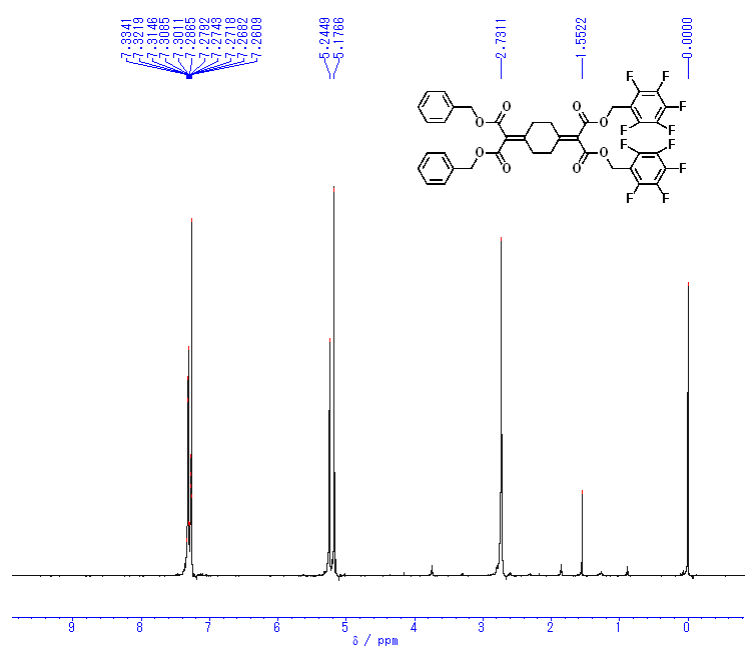

Polymer of 1c (poly-1c)

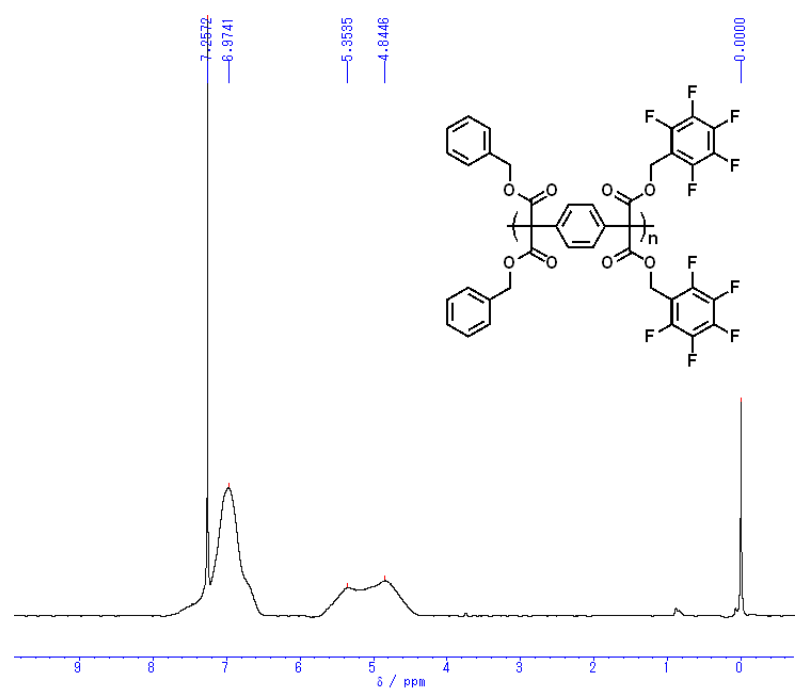

Figure S4. ${ }^{1} \mathrm{H}$ NMR spectra of 2, 3c, 1c, and polymer of $\mathbf{1 c}$ (poly-1c) in $\mathrm{CDCl}_{3}$. 
Pentafluorobenzyl Malonate

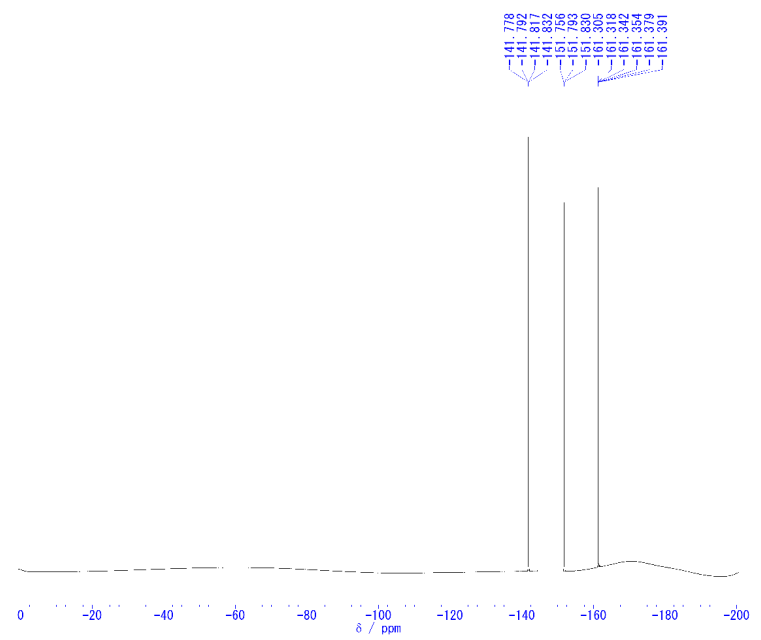

\section{Compound 3b}

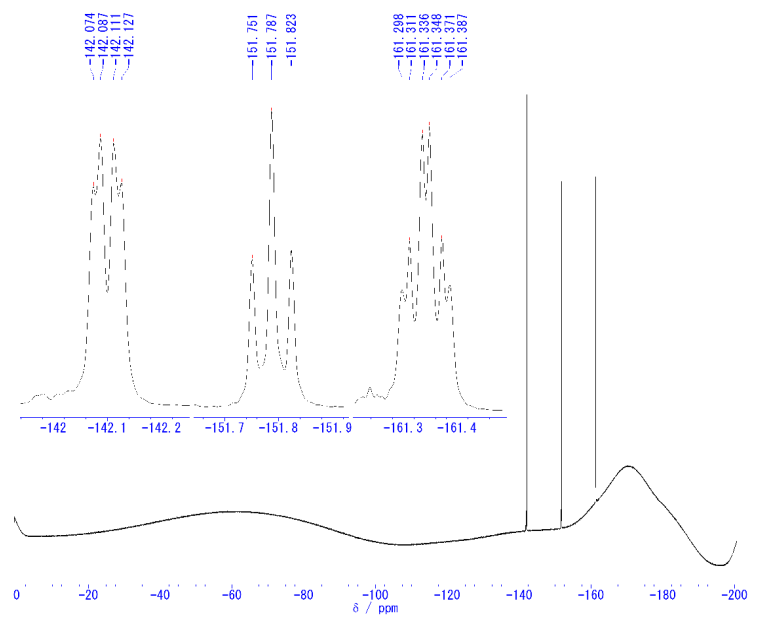

Compound 1b

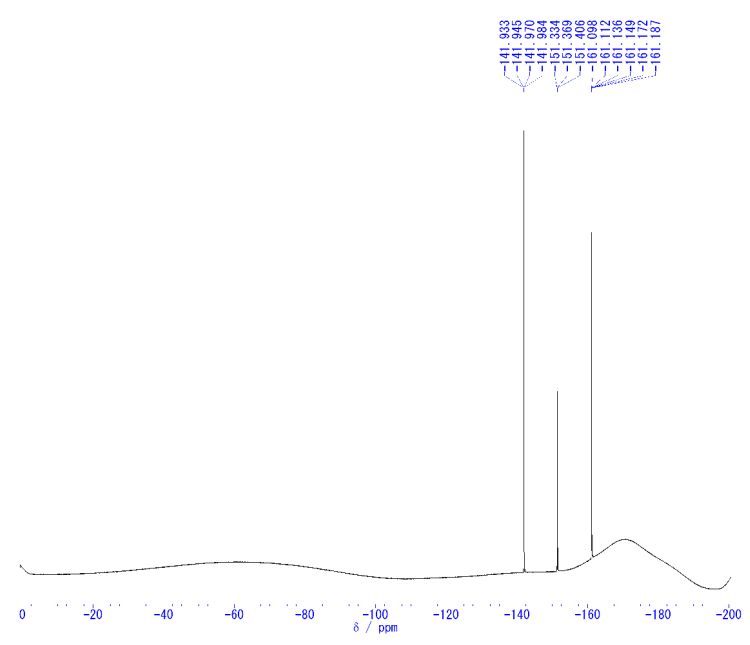

Figure S5. ${ }^{19} \mathrm{~F}$ NMR spectra of pentafluorobenzyl malonate, $\mathbf{3 b}$ and $\mathbf{1 b}$ in $\mathrm{CDCl}_{3}$. 
Compound 2

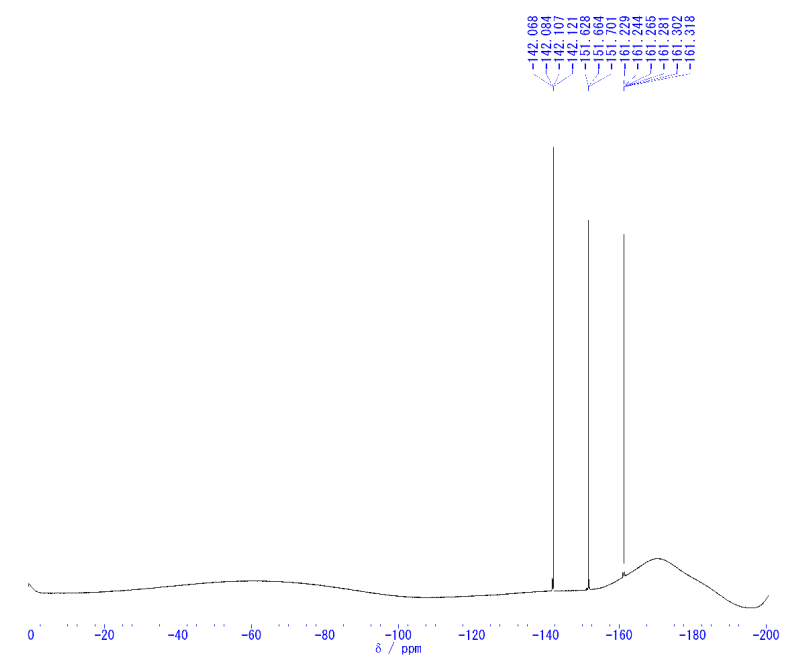

Compound 1c

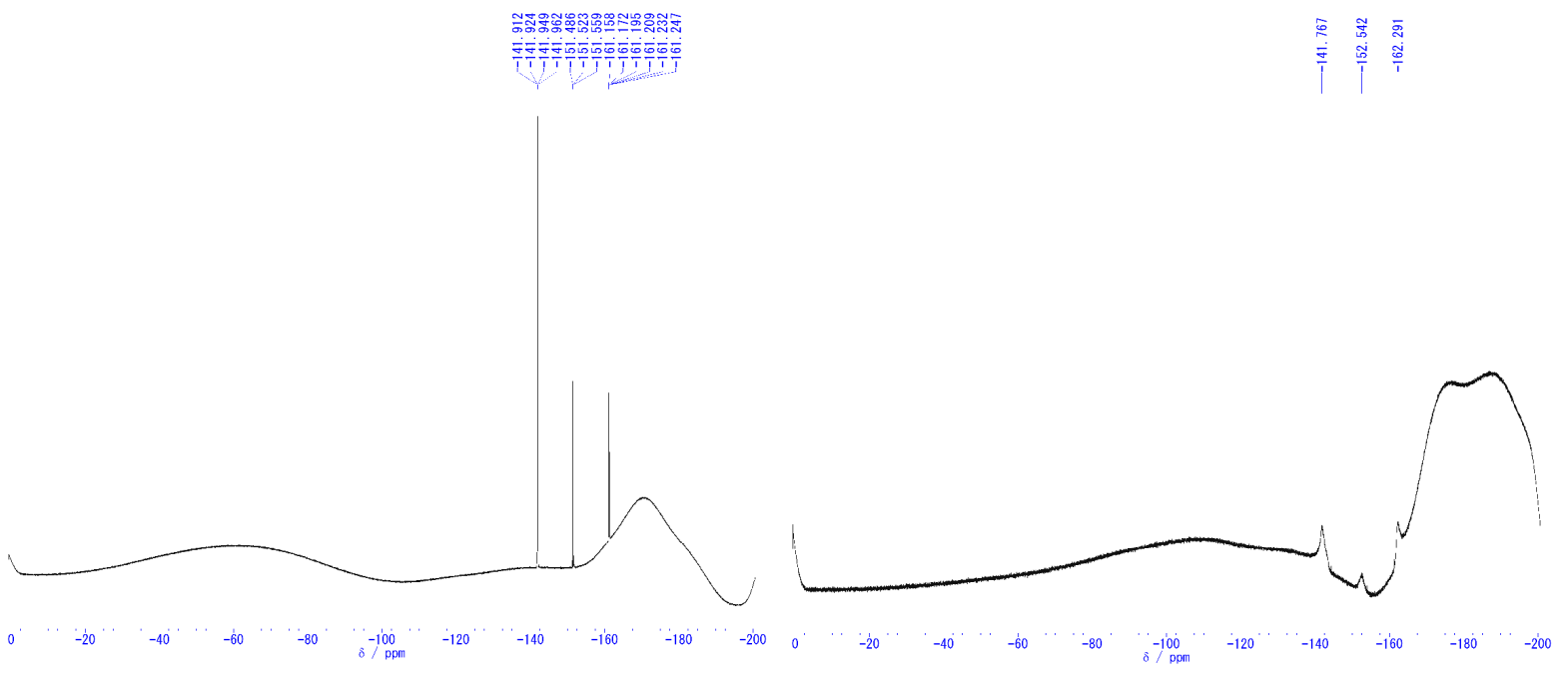

Figure S6. ${ }^{19} \mathrm{~F}$ NMR spectra of $\mathbf{2}, \mathbf{3 c}, \mathbf{1 c}$ and polymer of $\mathbf{1 c}\left(\right.$ poly-1c) in $\mathrm{CDCl}_{3}$. 